\title{
Sobre aislacionismo y excepcionalidad: Donald J. Trump, los Neoconservadores y el Derecho Internacional ${ }^{1}$
}

\author{
On Isolationism and Exceptionalism: Donald J. Trump, the Neoconservatives \\ and the International Law
}

\section{Ignacio Odriozola}

iodriozola@mpd.gov.ar

Master en Relaciones Internacionales por la Universidad de Buenos Aires (UBA). Estudios en la American University (AU), Washington College of Law. Miembro del Grupo Joven del Consejo Argentino para las Relaciones Internacionales (CARI).

Resumen: La noción de Estados Unidos como un país "excepcional” no sólo cuenta con un extenso desarrollo histórico y sociológico, sino también con un vasto respaldo político que ha penetrado distintas administraciones gubernamentales. Ello, invariablemente, ha trascendido a decisiones que repercuten en el posicionamiento de ese país con relación al Derecho Internacional. Sin embargo, hay quienes sostienen que, con la asunción de Donald J. Trump como nuevo presidente de los Estados Unidos, esta doctrina ha llegado a su fin. Por ello el autor propone explorar, inicialmente, el concepto y las distintas corrientes que han surgido en torno al "excepcionalismo americano", desde un enfoque histórico, político y en relaciones internacionales. Seguidamente, examina la relación entre el actual presidente norteamericano y esta noción, analiza el vínculo entre la nueva administración y el Derecho Internacional para, finalmente, responder el interrogante: ¿es el fin del 'excepcionalismo americano'?

Palabras claves: Estados Unidos - Excepcionalismo Americano - Donald J. Trump - Derecho Internacional - Neoconservadores

\begin{abstract}
The notion of the United States as an "exceptional" country not only has extensive historical and sociological development, but also a vast political backing that has penetrated different government administrations. This has invariably transcended decisions that affect the position of this country in relation to international law. However, there are those who argue that since the inauguration of Donald J. Trump as the new president of the United States, this doctrine
\end{abstract}

\footnotetext{
${ }^{1}$ Artículo enviado el 29.06.2017 y aceptado el 06.12.2017.
}

Número de página no utilizable para citar 
has come to an end. For this reason, the author proposes to explore, initially, the concept and the different movements that have arisen around "American exceptionalism", with a historical, political and international relations approach. Then examines the relationship between the current American president and this notion, analyzes the link between the new administration and the international law, and finally, tries to answer the question: Is it the end of 'American exceptionalism'?

Keywords: United States - American Exceptionalism - Donald J. Trump - International Law Neoconservatives.

\section{Introducción}

Todas los Estados del mundo tienen un lema, es decir, una norma que regula o parece regular la conducta estatal ${ }^{2}$ y que suele estamparse en el escudo heráldico de cada país naciente a modo de presentación o motivación: esto somos, esto pensamos, esto queremos. En el caso de Estados Unidos (EEUU), el Gran Sello contiene, antes bien, una frase que algunos consideran una premonición: un águila americana aferra en sus garras hojas de olivos y flechas, mientras muerde un pergamino que reza en latín "E pluribus unum”, que en su traducción al español significa: "De muchos, uno". 3

La condición de EEUU como país excepcional se encuentra instalada en el imaginario colectivo desde los albores de su historia, aun cuando tan sólo encarnaba un puñado de colonias díscolas estacionadas verticalmente en lo que hoy se denomina Costa Este.

Sin embargo, esta noción ha trascendido los escasos dos siglos de vida que Estados Unidos ostenta como nación independiente, ha sido abordada desde distintos campos de estudio y representa desde antaño un principio rector de su política exterior. De allí, que cuenta con una vasta literatura que pone el foco en enaltecer esa posición de distingo según la corriente políticofilosófica a la cual se adscribe.

No obstante, el 20 de enero de 2017, con el arribo del presidente Donald J. Trump al Salón Oval, distintos analistas han decretado -no sin razones- "el fin del excepcionalismo americano". Por lo tanto, el objeto del presente trabajo es, inicialmente, conceptualizar esta noción y a tal

Cfrme. Real Academia Española (RAE), disponible en: http://dle.rae.es/?id=N6HonBK

Si bien entre historiadores hay una profunda discusión respecto del sentido que debe atribuirse a este lema, lo cierto es que la posición que prevalece es aquella que sostiene que, "entre muchos, uno", responde a la idea del surgimiento de una nación fuerte y constituida, como resultado de la unión de trece Estados diferentes. Sobre este y otros aspectos de la discusión en cuestión, ver: Franzese, P. "E Pluribus Unum - From Many, One: In Unity There is Strength”, New Jersey Lawyer, 1995, Vol. 33, pp. 33-39. 
efecto realizaré un breve racconto histórico de esta doctrina e identificar distintas posturas al respecto. Una vez ello, nos focalizaremos en la posición del actual presidente estadounidense respecto de esta idea e intentaré demostrar porqué, desde la corriente neoconservadora y su relación con el Derecho Internacional, podría resultar desacertado ponerle coto a este concepto. Por último, intentando responder a la pregunta que encabeza esta presentación, ofreceré algunas reflexiones finales.

\subsection{God bless America}

Estados Unidos dice ser un Estado excepcional. Esta autor referencia es un tanto usual, según James W. Ceaser, hasta que se precisa su significado. Si bien ha adquirido fuerza con posterioridad a la Segunda Guerra Mundial y, aún más luego del fin de la Guerra Fría, revela un pasado histórico que a tenor de sus promotores se remonta hacia el Siglo XVII. En ese entonces, John Winthrop, uno de los líderes de las primeras oleadas migratorias que abandonaron Inglaterra para establecerse en la Colonia Bahía de Massachusetts (Nueva Inglaterra), describió al reciente asentamiento puritano como "the city on the hill" mientras aseguraba que "the eyes of all people are upon as". ${ }^{4}$

Los primeros años de la historia estadounidense no fueron ajenos a esta idea. De hecho, George Washington, padre fundador, afirmó desde temprano que Estados Unidos no debía atarse "con lazos artificiales a las ordinarias vicisitudes de la política [europea] o las ordinarias combinaciones y colisiones de sus amistades o enemistades. Nuestra situación desapegada y

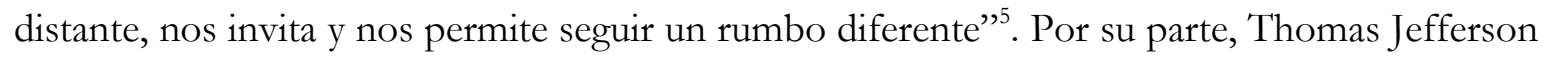
indicó que Estados Unidos, en tanto “imperio de la libertad”, no podía ser insensible y obviar que las circunstancias que agraciaron a su país, y les fueron negadas a otros, imponían el deber de actuar en favor de la humanidad, pues EEUU debía demostrar al mundo cuál es el grado de libertad y autonomía que una sociedad puede alcanzar. ${ }^{6}$

Años más tarde, sería el tratadista francés, Alexis de Tocqueville, quien materializaría con su obra "La democracia en América" el porvenir de la nación norteamericana. Allí precisó que la ausencia de un pasado feudal, su distancia con relación al sistema europeo, el espíritu republicano y la íntima unión entre el puritanismo religioso y la libertad, hacían que Estados Unidos fuera "excepcional".

4 Ceaser, J. W. "Origins and Character of American Exceptionalism”, American Exceptionalism: Is it real, is it good?, American Political Thought, (Chicago Journal, Spring 2012), 4.

5 Kissinger, Diplomacia (Barcelona: Bailen, 1996), 13.

6 Kissinger, H., World Order (Nueva York: Penguin, 2014), 236.

7 De Tocqueville, A., La democracia en América, trad. Dolores Sánchez de Aleu (Madrid: Alianza, 1989).

Número de página no utilizable para citar 
Sin embargo, recién hacia finales de 1950 nació el término que da nombre a esta doctrina de pensamiento. Puntualmente, Max Lerner, en su libro titulado “América como Civilización”, retomó los trabajos del antiguo líder del Partido Comunista Americano, Jay Lovestone, quien hizo referencia a la situación de excepcionalismo en que se encontraba Estados Unidos, dado su avanzado sistema capitalista, respecto de los demás países del mundo que se encaminaban inexorablemente hacia una revolución socialista ${ }^{8}$. Como veremos a continuación, el aspecto etimológico del excepcionalismo actual se aleja de la razón que dio pie a su denominación.

Finalmente, se asocia a Ronald Reagan como el exponente más elocuente de esta doctrina, y prueba de ello es su discurso de despedida, en enero de 1989, en que señaló:

He hablado de la ciudad brillante toda mi vida política, pero no sé si alguna vez comuniqué lo que vi cuando lo dije. En mi mente era una ciudad alta y orgullosa construida sobre rocas más fuertes que los océanos, el viento abarrotado, bendecida por Dios y repleta de gente de todo tipo viviendo en armonía y paz, una ciudad con puertos libres que zumbaban de comercio y creatividad, y si tenía que haber muros en la ciudad, ellos tenían puertas y las puertas estaban abiertas a cualquier persona con la voluntad y el corazón para llegar aquí. Así lo vi, y lo veo todavía. ${ }^{9}$

Merece destacarse que, tal como referíamos antes, la autoreferencia a una situación de distingo suele ser cotidiana. En rigor, desde un aspecto sociológico, el concepto de excepcionalidad no debe analizarse a partir de su mera enunciación, por cuanto la historia demuestra la existencia de otras naciones que se ven a sí mismas como excepcionales: basta con mencionar a los hebreos, quienes se consideran el "pueblo elegido" por Dios; los rusos, quienes ven su propia tierra como "la gran madre Rusia"; o los chinos, que denominan a su territorio "qhongguo", literalmente traducido como "Nación del Centro"10. Por lo tanto, este concepto debe abordarse por el significado o el alcance que se le otorga a la situación de excepcionalidad, pues en función de ello podrá identificarse por qué en el caso norteamericano dicho predicamento transmutará en verdaderas decisiones políticas.

Ahora bien, sin perjuicio de que la idea del excepcionalismo se encuentra firmemente arraigada a la cultura política del país desde antiguo, en Estados Unidos, inicialmente, la palabra excepcionalismo estuvo asociada al campo de la sociología -de allí el párrafo precedente-, ocasionalmente era enunciada por historiadores y también por académicos vinculados a Estudios

Kissinger, H., Diplomacia, 13.

Reagan, Ronald, Discurso de despedida a la Nación, 11 enero de 1989, disponible en: http://www.americanrhetoric.com/speeches/ronaldreaganfarewelladdress.html

10 Leveratto, Y., La teoría del excepcionalísmo americano en el mundo multipolar del siglo XXI, disponible en: https://www.academia.edu/7982716/La_teoría_del_excepcionalismo_americano_en_el_mundo_multipolar_del_siglo_X $\mathrm{XI}$ 
Americanos. No obstante, hoy día aparece en discursos políticos o columnas de diarios; se ha virilizado y se implementa, principalmente, para polarizar entre liberales y conservadores. ${ }^{11}$

Entonces, llegado a este punto debemos preguntarnos qué entendemos a partir de la palabra excepcionalismo y qué representa, para los Estados Unidos, ser excepcional. Con esto en claro, podremos avanzar y comprender por qué razón se habla del fin del excepcionalismo, desde la llegada de Trump a la Casa Blanca y, además, por qué cala profundamente en la posición política respecto del Derecho Internacional.

Cuando decimos que algo es excepcional, hacemos mención a aquello que se aparta de lo ordinario o que ocurre rara vez. La exégesis norteamericana sigue esta línea pues, en su sentido original, el excepcionalísimo implica que los EEUU son un país único y diferente al resto de los países del mundo $^{12}$. Ello, sin embargo, no significa necesariamente que sea superior a los demás: como indica Seymour Martin Lipset, cuando Tocqueville o ciertos escritores extranjeros emplearon el término "excepcional", pretendían sugerir que este país era cualitativamente distinto y no que era mejor a otros o que poseía una cultura por encima de aquellas. ${ }^{13}$

No obstante, las interpretaciones son variopintas y ello, por ejemplo, se ve reflejado en las expresiones de distintos presidentes norteamericanos. En tal sentido, Abraham Lincoln ha caracterizado a EEUU como "la última mejor esperanza del hombre en la tierra", George W. Bush (h) señaló que "América es el único calificado para liderar el mundo" mientras que, al ser consultado por su postura al respecto, Barack Obama, indicó: "Creo en el excepcionalismo americano, así como sospecho que los británicos creen en el excepcionalismo británico y los griegos creen en el excepcionalismo de Grecia". ${ }^{14}$

Por su parte, los puntos de vista también varían entre académicos de Política Exterior norteamericana, como Gordon Wood, de la Universidad Brown, quien destaca que el "destino americano" fue "convertirse en la piedra angular de la libertad en la tierra", 15 o Stephen M. Walt, de la Universidad de Harvard, quien considera al excepcionalismo americano "un mito" en tanto (esta idea) hace que "los demás países a menudo se alarmen por las políticas norteamericanas y frecuentemente se irriten al presenciar la hipocresía estadounidense", motivo por el cual

\footnotetext{
11 Iglesias Cavicchioli, M., "La Doctrina Neoconservadora y el Excepcionalísimo americano: una vía al unilateralismo y a la negación del Derecho Internacional”, Revista Electrónica de Estudios Internacionales, (Madrid: REEI, 2014), 4.

12 Kissinger, $\mathrm{H}$, World Order, 2.

13 Lipset, S. M., El excepcionalísmo norteamericano: una espada de dos filos (México D.F.: Fondo de Cultura Económica, 2000$), 15$.

14 Lincoln, Abraham, Mensaje anual al Congreso Americano, $1^{\circ}$ de diciembre de 1862, http://showcase.netins.net/web/creative/lincoln/speeches/congress.htm; Iglesias Cavicchioli, M., "La Doctrina Neoconservadora...", 2; The Withe House, Office of the Press Secretary, press release, April 4, 2009, disponible en: http://www.whitehouse.gov/the_press_office/News-Conference-By-President-Obama-4-04-2009/

15 Wood, G, The Idea of America: Reflections on the birth of the United States (Nueva York: Penguin, 2011), 321.
} 
considera que la política exterior de EEUU “sería más eficaz si los americanos estuviesen menos convencidos de sus virtudes únicas y menos ansiosos por proclamarlas". ${ }^{16}$

En otro orden, esta doctrina puede analizarse desde la corriente neoaislacionista, apoyada por aquellos que interpretan el excepcionalismo en clave de insularidad y que, por tanto, conceden al aspecto geográfico estadounidense una relevancia sustancial que lo distingue de otros países ${ }^{17}$. Igualmente, la visión internacionalista wilsoniana entiende que EEUU es un bastión fundamental, sino el principal impulsor, de un orden mundial liberal establecido sobre la estructura de un sistema global de economía, comercio y políticas democráticas liberales. ${ }^{18}$

Evidentemente, al citar distintas referencias se entrevé que las posturas cambian según la corriente político-filosófica que se respalda y, si bien estos comentarios no atinen a representar a la generalidad de ellas, cuanto menos permiten apreciar las diferentes interpretaciones que merece el excepcionalismo americano.

Hasta aquí, hemos caracterizado a esta doctrina desde enfoques que no han sido etiquetados, sino que reflejan opiniones -aunque ellas no sean inocentes-, trabajos académicos del campo de la historia, la sociología o los asuntos exteriores. Sin embargo, debemos ahondar en otras cuestiones para resolver si, desde la asunción de Trump como presidente, todo esto ha llegado a su fin.

\subsection{Make America Great Again}

Se dice que Donald J. Trump se ha encargado, incluso antes de ser presidente, de poner fin al excepcionalismo americano. Ello no es casual y, por cierto, tampoco encierra grandes elucubraciones: fue él mismo quien rechazó esta doctrina cuando, en abril de 2015, mientras se posicionaba como candidato a los próximos comicios presidenciales, expresó frente a activistas del Tea Party en Houston, Texas, que los americanos -al defender su excepcionalidad- insultan al mundo. ${ }^{19}$

Semejante afirmación no representa la única en que se sustenta esta idea. De hecho, el flamante presidente continuamente ha procurado dejar en claro su postura respecto de que, Estados Unidos, debe considerarse a sí mismo tan sólo un actor más en la arena mundial. Entre otras

16 Walt, S.M., “The Myth of American Exceptionalism”, Foreign Policy, November, 2011, http://www.foreignpolicy.com/articles/2011/10/11/the_myth_of_american_exceptionalism?page=0,0

17 Sobre este y otros aspectos de la corriente neoaislacionista: Nau, H, At Home Abroad; Identity and Power in American Foreign Policy (Ithaca: Cornell University Press, 2002), 44-48.

18 Sobre este y otros aspectos de la corriente internacionalista wilsoniana: "El presidente Wilson y los Neoconservadores", Politica Exterior, vol. 18, n 97 (enero/febrero 2004), 95-110.

19 Wertheim, S. "Trump and American exceptionalism. Why a Crippled America is something new", Foreing Affairs, 3 de enero de 2017, disponible en: https://www.foreignaffairs.com/articles/united-states/2017-01-03/trump-and-americanexceptionalism 
cosas, y a modo de ejemplo, Trump indicó que descartará la promoción de la democracia en el extranjero: "I don't think we're a very good messenger" 20 . Esta decisión, además de ubicar a EEUU en pie de igualdad con otros países, resultaría impensada en cualquier promotor de la doctrina del excepcionalismo americano, en tanto significaría dejar de lado -o cuanto menos relegar a un segundo plano- el marketing del sistema que, por antonomasia, ha caracterizado a la nación del norte desde sus albores: la democracia republicana liberal.

Trump no sólo confirma su postura antiexcepcionalista al alejar a la democracia de su agenda, sino que la refuerza cuando asocia a EEUU con el "bufón” del mundo -"Our country is a laughingstock... All over the world, they're laughing"- puesto que, en su concepción, Estados Unidos se cree superior al resto de la comunidad internacional pero lejos se encuentra de estar a la altura de los superiores. En efecto, para materializar esta idea, se ha puesto en los pies de los viajeros que luego de abandonar suntuosos aeropuertos en China, Qatar o en Dubai, aterrizan en JFK, La Guardia, Newark o en LAX y tan sólo ven escombros. Y concluye su conjetura diciendo: “we've become a third world country". De igual manera, se ha sincerado con su electorado -probablemente con fines proselitistas-, dejando en ridículo a su país frente al mundo, al afirmar que la invasión a Irak no tuvo ningún sentido porque, a fin de cuentas, "United States did not take the oil before getting out $^{, 21}$. Declaraciones de esta índole, que por cierto representan sólo algunas de las efectuadas por Trump, sin ir muy lejos, resultarían inimaginables en boca de su predecesor, el demócrata Barack Obama, quien consideraba a Estados Unidos la "envidia del mundo" y fue, sin perjuicio de sus críticas a la derecha, el presidente que más frecuentemente utilizó la palabra "excepcional" para caracterizar a su país. ${ }^{22}$

Como mencionaba con anterioridad, la interpretación que ha primado en torno a estas manifestaciones deletéreas que Trump expresa en discursos públicos o a través de los medios de comunicación, sumado al propio abordaje que él ha hecho sobre este asunto, han contribuido a concluir, tal vez presurosamente, el fin de una doctrina que ha marcado la historia de Estados Unidos.

Sin embargo, verdad es que las palabras que no van seguidas de hechos poco valen. Por ello, no basta con reducir semejante giro idiosincrático en algunas frases. Menos aun cuando se aborda semejante asunto como es el excepcionalismo americano, doctrina que no prescribe un sólo

$20 \mathrm{Al}$ ser entrevistado por el periodista David Sanger, de The New York Times, éste preguntó a Trump si se diferenciaría de George W. Bush, quien enarboló su política exterior sobre la base de "libertad y democracia" para atraer aliados. El actual presidente americano señaló que desconocía que Estados Unidos tuviese el derecho de dar conferencias sobre este asunto dentro de las fronteras de otros países. Entrevista completa disponible en: https://www.nytimes.com/2016/07/22/us/politics/donald-trump-foreign-policy-interview.html?_r=0

21 Discurso de cierre de campaña en la Costa del Golfo en Florida, el 8 de noviembre de 2016. Discurso completo: http://www.latimes.com/nation/politics/trailguide/la-na-trailguide-updates-trump-s-closing-argument-the-u-sis1478540304-htmlstory.html; Debate Presidencial, 27 de septiembre de 2016. Disponible en: http://www.huffingtonpost.com/entry/donald-trump-airports-third-world_us_57ebf01ee4b082aad9b865b2; Wertheim, S., "Trump and American exceptionalism...".

22 Discurso de cierre de campaña..., 8 de noviembre de 2016. 
curso de acción, sino que, por el contrario, ha demostrado su capacidad de justificar decisiones diametralmente opuestas en materia de política exterior, como la separación político-militar del viejo mundo europeo, antes de la Segunda Guerra Mundial, mas luego la legitimidad para intervenir en la referida contienda mundial. ${ }^{23}$

En rigor, catedráticos en la materia como Arturo López Levy, al analizar los slogans de campaña electoral de Trump, demuestra la presencia de elementos que se dirigen a fortalecer tácitamente la idea del excepcionalismo americano. Así, indica López Levy, el mensaje de "Make America great again" tuvo un claro enfoque doméstico, y en particular retomaba la idea de Ronald Reagan de reforzar los valores del "Nacionalismo blanco": aquella mayoría blanca anglosajona y protestante que se encargó de definir la identidad estadounidense, y que, con la crisis de 2008 y la presidencia de Barack Obama, sintió ser olvidada. Por su parte, la propuesta de "America First" refleja un posicionamiento en el plano internacional, en la política exterior y, según López Levy, ello obedece al deber de todo presidente americano de poner los "intereses y los valores de ésta nación en primer lugar". ${ }^{24}$

De hecho, estas directrices tan nacionalistas como populistas, a criterio de Javier Redondo, son naturales y cotidianas en la historia Norteamericana. Y agrega que, conforme Lipset, son un rasgo del credo y del excepcionalismo americano, resumidos en cinco términos: libertad, igualitarismo, individualismo, libre comercio y populismo, elementos todos que -entiende Redondo- son encarnados en la figura de Donald J. Trump. De allí que, concluye, el presidente americano encarna las esencias del pueblo y construye un relato en torno a los valores fundacionales de su país. ${ }^{25}$

Es razonable deducir, entonces, que el excepcionalismo americano encierra en sí mismo el nacionalismo que hoy exacerba Trump pues, evidentemente, la historia estadounidense da cuenta de que esta doctrina, en lo superficial, posee distintas caras y tiene la capacidad de adoptar distintas formas, pero que, en lo sustancial, mantienen las estructuras básicas que la han constituido y que han acompañado a la política exterior de EEUU desde sus orígenes.

\subsection{In God we trust}

Esto invita a preguntarnos si, ante una doctrina cuya ambigüedad de interpretaciones suele ser tal, cabe hacer referencia a su fin. Como ya dije, por fuera de las palabras, serán los hechos traducidos en políticas o en gestos- aquellos que, objetivamente, podrán demostrar si la "excepcionalidad" de Estados Unidos ha concluido. Y, en tal sentido, a poco de analizar los

23 Discurso de cierre de campaña..., 8 de noviembre de 2016.

24 “¿Qué significa 'Make America Great Again' y 'America First'?”, Sputnik,

https://mundo.sputniknews.com/politica/201611111064778402-make-america-graet-again-trump/

25 "Trump Profana el Templo", El Mundo,

http://www.elmundo.es/opinion/2016/10/27/5810dda5268e3e05668b4651.html

Número de página no utilizable para citar 
primeros pasos de Trump en la Casa Blanca, vemos que la conformación de su Gabinete cuenta con ciertos defensores -que mencionaré posteriormente- del ala más radical del excepcionalismo, al menos en lo que al Derecho Internacional respecta: los Neoconservadores.

La corriente neoconservadora, cuya génesis suele asociarse a la Doctrina Truman, se ha reivindicado como heredera de las mejores esencias nacionales de los Estados Unidos. De hecho, el discurso de Truman del 12 de marzo de 1947, y el propio Truman como partidario del excepcionalísimo americano, son dos referencias importantes en la representación de las relaciones internacionales y de la política exterior neoconservadora. Puntualmente, su interpretación del excepcionalismo americano se centra en la universalidad y en la superioridad; nociones rectoras que acaparan todos los aspectos restantes que giran en torno a esta corriente. ${ }^{26}$

Los neoconservadores consideran que los EEUU son la primera y la única nación universal que existe. Sustentados en la noción del Destino Manifiesto, que les ha endilgado una "misión sagrada" de escala global, creen tener el deber de desarrollar su identidad plenamente y exportarla, junto con la democracia, al resto del mundo (con el fin de la Guerra Fría, Wattenberg denominó esta corriente como Neo Manifest Destiny, en tanto era momento de que la política exterior norteamericana pasara de una política exterior anticomunista a una prodemocrática). En palabras de Henry Kissinger, desde un principio "the real challenge of American engagement abroad was not foreign policy in the traditional sense but a project of spreading values that it believed all other people aspired to replicate". ${ }^{27}$

Asimismo, para los neoconservadores, Estados Unidos no sólo es un país único y cualitativamente diferente en razón de su rechazo originario al sistema europeo y por las particularidades propias de su sistema político, como creía Alexis de Tocqueville, sino que son superiores al resto. Esta superioridad, radica en dos aspectos: en los valores y principios morales que pregona y en el poder militar. ${ }^{28}$

Respecto de los valores y la moral, los neoconservadores parten de una lógica binaria: el bien y el mal. Claro está que EEUU como representante axiomático de la democracia occidental se encuentra del lado del bien mientras que los Estados Canallas (o Rogue States), usualmente vinculados con tiranías poseedoras de armas de destrucción masivas o ligados a redes terroristas, se hallan del lado del mal. Las bondades norteamericanas, a tenor de esta corriente, se reflejan en los valores superiores que persiguen y que son distintos a los del resto del mundo. Por eso, es dable suponer que la postura neoconservadora entiende que lo bueno para Estados Unidos, es por definición bueno para el mundo. ${ }^{29}$

26 Iglesias Cavicchioli, M., "La Doctrina Neoconservadora y el Excepcionalísimo americano...”, 5.

27 Kissinger, H., World Order, 234.

28 De Tocqueville, A., La democracia en América, 5.

29 Bardaji, R. "La virtud de la hegemonía americana”, Cuadernos de Pensamiento Político, No. 1 (Madrid, 2003), 161.

Número de página no utilizable para citar 
De igual manera, los neoconservadores observan al poder militar como un fiel reflejo de la superioridad. La fuerza militar debe ser sostenida y aumentada pues, de ella depende la supervivencia de los valores y los principios morales. Inversamente, la acción militar es entendida como el medio para difundir y expandir el predicamento americano. En tal sentido, Elliot Abrams afirma que cuando los EEUU son fuertes militarmente la democracia avanza en el mundo: "Maintaining American military strength is not only a vital to a succesful foreing policy. The 1970's and 1980's demonstrated that the success of democracy in the world is directly related to the strength"."

Así las cosas, las dimensiones que hacen a la excepcionalidad que pregona el neoconservadurismo lo obligan como tal a actuar de forma excepcional en la escena internacional. Entonces, surge así la tercera dimensión sobre la cual se apoya la concepción neoconservadora, el unilateralismo americano en política exterior: la responsabilidad hegemónica, que carecen el resto de los Estados, impone a EEUU obviar todo sometimiento o prohibición del Derecho Internacional y, por tanto, lo obliga a sortear cualquier limitación proveniente de los mecanismos multilaterales e institucionalizados. ${ }^{31}$

Por lo tanto, los neoconservadores, a diferencia del resto de las escuelas, no consideran al unilateralismo como última ratio o como una opción al alcance de los EEUU ante situaciones concretas y una vez agotadas otras vías multilaterales. Por el contrario, el unilateralismo es una obligación impuesta por la realidad internacional y no una opción táctica más a disposición de la política exterior, pasible de ser condicionante de sus propuestas transformadoras. ${ }^{32}$

Ahora bien, es momento de adentrarnos en algunos de los nombramientos que ha efectuado Trump a cargos públicos de máxima relevancia para los Estados Unidos. Estos, en virtud de posturas que han adoptado públicamente podrían asimilarse -al menos de manera temprana- a personalidades que respaldan la corriente neoconservadora.

Así, en primer lugar, podemos mencionar al Fiscal General Jeff Sessions. El ex Senador por el Estado de Alabama desde 1997, por ese entonces -y aún con su actual cargo- ha tenido una posición imperturbable respecto de cualquier legislación que intente regularizar la situación de todo migrante que se encuentre irregularmente en el país. Incluso, ha sido el principal promotor de la campaña de desfinanciamiento de las "ciudades santuario" 33 y de la extensión del muro

\footnotetext{
Abrams, E., Security and Sacrifice: Isolation, Intervention and American Foreign Policy (Indianapolis: Hudson Institute, 1995$), 118$.

Iglesias Cavicchioli, M., "La Doctrina Neoconservadora y el Excepcionalísimo americano...", 8.

Kagan, R., Poder y debilidad. Estados Unidos y Europa en el nuevo orden mundial (Madrid: Taurus, 2003), 44.

"Ciudades santuario" se denomina a muchas de las ciudades consideradas como amigables con los inmigrantes. Los gobiernos locales no expresan abiertamente su bienvenida a los inmigrantes ilegales, sin embargo se dice que su trato hacia ellos es menos discriminatorio que en otras ciudades. En las ciudades santuario, tienden a dar más apoyo a los inmigrantes ilegales alrededor de la comunidad. Algunos ejemplos pueden incluir activistas inmigrantes y grupos de la iglesia. Sin embargo también existen miembros de la comunidad que desaprueban grandemente a los ilegales y lo expresan. Ciudades estadounidenses catalogadas como santuario son: San Diego, Los Ángeles, San Francisco, Miami, Chicago, Seattle,

Houston, Phoenix, Austin, Dallas, Washington D.C., Detroit, Salt Lake City, Minneapolis, Baltimore, Portland (ambas
} 
separador de la frontera con México, mientras que, en materia de política exterior, Sessions se ha manifestado -al igual que el asesor del Fiscal General de los Estados Unidos en la Era Bush (h), John Yoo- a favor de mantener la prisión de Guantánamo, en Cuba, ha votado en contra de una legislación que intentaba prohibir "los tratos crueles, inhumanos o degradantes" de sus prisioneras y se ha mostrado escéptico respecto del cambio climático. ${ }^{34}$

Por su parte, al frente de la Agencia Central de Inteligencia (CIA), Trump designó a Mike Pompeo, ex representante del Estado de Kansas y miembro del ultraconservador Tea Party, acérrimo opositor a la política exterior de Barack Obama - principalmente al Acuerdo Nuclear con Irán, país al que ha denominado "promotor del terrorismo"- e impulsor de la tesis que sostiene la presunta connivencia entre los líderes musulmanes radicados en Estados Unidos y los ataques yihadistas. También, al igual que Sessions, se ha opuesto al cierre de Guantánamo y en 2009 propuso volver a las grabaciones de llamadas domésticas. ${ }^{35}$

En otro orden, quien asumió la Secretaría de Estado, órgano encargado de las Relaciones Exteriores estadounidenses, es Rex Tillerson, republicano y ex presidente de la firma petrolera Exxon Mobile Corporation. Entre sus posturas más controvertidas se encuentra su negación respecto del cambio climático y las consecuencias que éste acarrea, así como su opinión (y posición) en relación con las sanciones impuestas a través de foros multilaterales que, por cierto, se compadece con la estrecha relación que posee con el presidente de la Federación Rusa, Vladimir Putin ${ }^{36}$. A su vez, en 2011, mientras presidía la referida petrolera, y aún contra las intenciones de la Casa Blanca de estabilizar la situación interna de Irak, ha sido acusado de intervencionista al firmar acuerdos para favorecer el intercambio de crudo con la Región Autónoma del Kurdistán de Irak, a espaldas del Gobierno de Bagdad. ${ }^{37}$

Maine y Oregón), Denver, New York City, Chicago y todo el estado de New Jersey. Algunas desaprueban entrar en esta categoría, y claman por ser más estrictos con la ley migratoria y su implementación. Las ciudades pueden tener políticas formales e informales de santuario. La formalidad es lograda cuando la municipalidad aprueba lago por escrito. Usualmente comienza como una ordenanza, luego pasa a ser orden, resolución y por último política. Una política informal de santuario no es escrita pero es bien conocida entre los trabajadores de la ciudad o condado. Diferente a las políticas de santuario formales, no hay registros públicos de ella. La gente sabe de las políticas informales usualmente por declaraciones de algún funcionario público o por su alrededor. Para mayor desarrollo véase:

http://www.immigrationunitedstates.org/pages/ciudades-santuario.html

34 "Quién es Jeff Sessions, el fiscal general de Estados Unidos que está en la mira por sus conversaciones con un embajador ruso", BBC Mundo, disponible en: http://www.bbc.com/mundo/noticias-internacional-38034154

35 "Mike Pompeo, Sharp Critic of Hillary Clinton, Is Trump's Pick to Lead C.I.A", New York Times, disponible en: https://www.nytimes.com/2016/11/19/us/politics/donald-trump-mike-pompeo-cia.html

36 El informe en cuestión puede examinarse en: "The Exxonmobil-xto merger: impact on u.s. Energy markets", disponible en: https://www.gpo.gov/fdsys/pkg/CHRG111hhrg76003/pdf/CHRG-111hhrg76003.pdf; "How Exxon CEO Tillerson feels about sanctions (and other Secretary-related matters)", Dallas Business Journal, disponbile en: http://www.bizjournals.com/dallas/news/2016/12/06/exxon-ceo-tillerson-secretary-of-state.html

37 El informe donde indica su postura respecto del cambio climático puede examinarse en: "The Exxonmobil-xto merger: impact on u.s. Energy markets", disponible en: https://www.gpo.gov/fdsys/pkg/CHRG111hhrg76003/pdf/CHRG111hhrg76003.pdf; "How Exxon CEO Tillerson feels about sanctions (and other Secretary-related matters)", Dallas Business Journal, disponbile en: http:/ /www.bizjournals.com/dallas/news/2016/12/06/exxon-ceo-tillerson-secretary-ofstate.html; "How Exxon, under Rex Tillerson, won Iraqi oil fields and nearly lost Iraq", Washington Post, disponible en: 
Por último, otro de los hombres que ingresó con la nueva administración fue Steve Bannon, como Jefe Estratega de la Casa Blanca, cargo integrante del Consejo Nacional de Seguridad órgano creado justamente por Harry Truman en 1947 con la firma del National Security Act-. Además de haber liderado la estrategia de campaña de Donald J. Trump, Bannon, máximo asesor del presidente, se ha expresado públicamente como islamofóbico e impulsor de la guerra global contra el radicalismo de ésta religión. Ha sido etiquetado por los medios como el monje negro y fue resistido desde su nombramiento; Bannon es, además, un declarado "supremacista blanco", creador de la frase de campaña "America First" y promotor de medidas como las modificaciones a las leyes migratorias y de la salida Norteamericana de la OTAN. ${ }^{38}$

Entonces bien, estos son solo algunos de los nuevos nombres que ha incorporado en su administración el flamante presidente de Estados Unidos. Desde ya, una limitación de espacio impide un análisis exhaustivo de cada uno de los nuevos integrantes del Gabinete de Donald J. Trump, sin embargo, a poco de examinar sus actuaciones o sus propuestas, entiendo que las personalidades seleccionadas reflejan y representan, tanto por los cargos que ocupan y han ocupado, una clara toma de posición respecto de la corriente doctrinal que se ha adoptado entorno a la noción del excepcionalismo americano. Es que, de uno u otro modo, ellos han demostrado públicamente, ya sea antes de o con posterioridad a la asunción de sus mandatos, y a través de acciones concretas, gestos o decisiones, sostener los principios de universalidad, superioridad y unilateralismo sobre el cual se erige el neoconservadurismo de Estados Unidos. No obstante, la idea de este trabajo es desentrañar qué implica o cómo se traducen los efectos de apoyar esta posición en materia de Derecho Internacional. Así, con el objeto de explorar esta cuestión, tendremos que adentrarnos en algunas medidas en materia de política exterior adoptadas en los últimos años y en estos primeros meses de mandato para, finalmente, concluir $\rightarrow$ no- si estamos ante el fin del excepcionalismo americano.

\section{Excepcionalismo neoconservador y el Derecho Internacional}

Debo aclarar que sobre este punto en particular no abunda la literatura académica y, por cierto, el abordaje que se ha dado a esta cuestión suele inferirse a partir de la visión de las relaciones internacionales. De allí, afirma Iglesias Cavicchioli, que la falta de esfuerzos de los neoconservadores por elaborar una concepción sistemática del Derecho Internacional ha

https://www.washingtonpost.com/world/national-security/how-exxon-under-rex-tillerson-won-iraqi-oil-fieldsandnearly-lost-iraq/2017/01/09/5f6efa28-d40c-11e6-9cb0-54ab630851e8_story.html?utm_term=.b9c4d2d38b4f

38 "Steve Bannon: who is Trump's key adviser?", BBC News, disponible en: http://www.bbc.com/news/election-us201637971742 
significado que los académicos traten la cuestión "más de manera implícita que explícita y de forma más tangencial que directa". ${ }^{39}$

Los neoconservadores parten, por consiguiente, de "la consideración del Derecho Internacional como un epifenómeno del poder del que no tendría autonomía" ${ }^{40}$, pues en el sustrato filosófico de la concepción neoconservadora, el poder estatal se encuentra por sobre el derecho en las relaciones internacionales. Por ende, para este enfoque no existe más que una visión instrumental del Derecho Internacional, en tanto herramienta al servicio del poder que, según la voluntad (concepción voluntarista) de los Estados Unidos por ejercerlo, será (o no) aplicable. Incluso, hay quienes sostienen la negación de este derecho, como el diplomático John Bolton, quien ha afirmado que: "International Law is not law; it is a series of political and moral arrangements that stand or fall on their own merits, and anything else is simple theology and superstiton masquerading as law". ${ }^{41}$

Probablemente, lo interesante de este punto es la actitud contradictoria norteamericana. Es que a pesar de negar el Derecho internacional, EEUU suele tener un rol activo en la producción normativa o instrumental; apunta a que otros Estados se "obliguen a obligarse" e incluso los conmina a asumir sus deberes mientras que, regularmente, queda exento de responsabilidad ante su inobservancia o, peor aún, abandona los procesos de creación normativa o institucional que fervorosamente ha encabezado. No sorprende, entonces, cuando Robert Kagan, afirma que el Derecho Internacional está al "servicio de los intereses y valores de las tiranías" perjudicando "los intereses y valores de los Estados democráticos". ${ }^{2}$

Expresiones como estas han llevado a la corriente neoconservadora a redefinir, siempre teniendo en mira la consecución de sus fines, normas basales y sustanciales para la disciplina. A continuación, me focalizaré en analizar los principios de (1) igualdad soberana de los estados, (2) de no injerencia en los asuntos internos, (3) de intervención humanitaria y (4) la aplicación de las "leyes de la guerra".

39 Kissinger, H., World Order, 11.

40 Es menester aclarar que la corriente neoconservadora ha sido, históricamente, respaldada por la Escuela de New Haven o Escuela de Yale- que, muy resumidamente, podría caracterizarse como aquella que afirma que el derecho debe ser entendido como continuo proceso legal de decisión autorizada y de control, que permite la legitimación de cualquier conducta efectiva fuera de los estrechos confines del texto que, tras haber sido previa y cuidadosamente examinada, sea capaz de potenciar la consecución del "Sollen" -el deber ser-, sin poner en peligro el orden comunitario. Sobre este punto y otros aspectos de la Escuela New Haven ver: De la Rasilla del Moral, Ignacio, "Apuntes críticos para una Teoría Neoconservadora del Derecho Internacional”, Revue québécoise de droit international, 2007. Vol. 20.1. Disponible en: https://www.sqdi.org/wp-content/uploads/20.1_del-moral.pdf

41 Woolsey, R., "Introduction", en Woolsey (ed), The National Interest on International Law and Order (New Bunswick: Transaction, 2003), 7-8; Bolton, J., "'Is there really Law' in International Affairs?", Transnational Law and Contemporary Problems, Vol. 10:1, (Kent, 2000), 48.

42 Kagan, R., El retorno de la Historia y el fin de los sueños, (Madrid: Taurus, 2008), 102. Ver también: Tasioulas, J., "Legitimacy of International Law", en Bensson y Tasioulas (edit.) The Philosopby of International Law (Oxford: Oxford University Press, 2012), 103. Respecto de la contradicción referida, sin ir muy lejos en el tiempo, la Administración Bush, luego de que la Administración de Clinton impulsara la creación de la Corte Penal Internacional y la concreción del Estatuto de Roma, declinó la ratificación del tratado internacional que favorecía la creación del referido tribunal con jurisdicción universal. 
El principio de igualdad soberana de los Estados, cuya génesis da origen al mismo Derecho Internacional, se remonta a la Paz de Westfalia de 1648. Aunque receptado en el art. 2.1 de la Carta de Naciones Unidas, ha sido redefinido de cuajo por la corriente neoconservadora. En breves líneas, podría decirse que ellos interpretan a la soberanía como una cualidad propia o, eventualmente extensible a quienes merecen ser considerados iguales, pero desconocen la ajena cuando resulta conveniente. En otras palabras, limitan la soberanía de los Estados autocráticos pues resulta inconcebible que un rogue state tenga un poder soberano equiparable al de una democracia. De allí que, ante la representación de una amenaza a su seguridad nacional, el excepcionalismo neoconservador no duda en que la soberanía debe decaer automáticamente y el cambio de régimen se torna una opción asequible. ${ }^{43}$

En esta misma línea, es sensato que autores neoconservadores como Joshua Muravchik, se hayan mostrado partidarios -desde un inicio- de la vulneración del principio de no injerencia en los asuntos internos mediante el fomento de la llamada "intervención humanitaria" en Kosovo, hacia finales de la década de los ' $90^{44}$. Esta clase de acciones resultan razonables con los fundamentos basales de la corriente en cuestión, por cuanto acompañan la lógica estatocéntrica, unilateralista y hegemónica. En contraposición, no apoyan la noción de Responsabilidad de Proteger (R2P por sus siglas en inglés), en tanto esta concepción -consecuente de la precitada "intervención humanitaria"- vino a legalizar y a institucionalizar la injerencia internacional, bajo ciertas exigencias como la potencial imposibilidad estatal de proteger a la población civil frente a la comisión de crímenes de guerra, genocidio, lesa humanidad o depuración étnica. ${ }^{45}$

En definitiva, el apoyo a la primera y la desaprobación de la segunda, obedece a la consideración ambivalente de la noción de soberanía: la intervención humanitaria responde a una mirada tradicional de la seguridad, mientras que la R2P, proviene del concepto liberal de seguridad humana y al deber internacional de reaccionar ante la violación masiva de derechos humanos. ${ }^{46}$

Siguiendo este análisis, el principio de probibición del uso de la fuerza ha sido objeto de severos embates por parte del a concepción neoconservadora. En efecto, desde la Carta de San Francisco en 1945, han puesto reiteradamente en tela de juicio las normas que regulan el ius ad bellum o derecho a la guerra. Sin embargo, la arremetida más tangible contra la referida

43 El caso de Irak II, en el año 2003, es a las claras el evento reciente más palpable y cercano a nuestros días en tanto, so pretexto de la existencia de armas de destrucción masiva (ADM), invadió el país de Oriente Próximo no sólo sin lograr el apoyo de la comunidad internacional, sino implementando un retorcido argumento: el incumplimiento, por parte de Irak, de la Resolución 678/1990 del Consejo de Seguridad, que había sido adoptada por el mentado órgano de Naciones Unidas en el marco de Irak I, trece años antes.

44 Muravchik, J., The Imperative of American Leadership: A challenge to Neo-isolationism, (Washington: AEI Press, 1991), 161- 62.

45 Sobre este punto, no puede dejar de mencionarse que, en el seno del Consejo de Seguridad, EEUU ha votado a favor de las únicas dos Resoluciones de este órgano que han favorecido la intervención militar bajo la noción de R2P. Ambas refieren al Caso Libia, la 1970/2011 y la 1973/2011. Aun así, debe aclararse que la acción armada fue llevada a cabo principalmente por Francia y en segundo lugar Gran Bretaña.

46 Para mayor desarrollo ver: ICISS, The Responsibility to Protect: Report of the International Commission on International and State Sovereignty, International Development Research Center, (Ottawa, December 2011).

Número de página no utilizable para citar 
prohibición ha surgido con la noción de los "ataques preventivos", considerada por autores como Danny Cooper una respuesta ad hoc al 11-S, y por otros, como Iglesias Cavicchioli, quien entiende que ésta ya era parte del acervo ideológico neoconservador desde los años ' $90 .{ }^{47}$ Sea del modo en que sea, este enfoque coincide en que, la guerra de disuasión propia de la era de Guerra Fría, debe desecharse ya que no es posible esperar que la amenaza se consume o esté a punto de materializarse. Así, han extendido o ampliado implícitamente el artículo 51 de la Carta Naciones Unidas sobre el derecho a la legítima defensa, cuya naturaleza proactiva y ofensiva, frente a la tradicional concepción reactiva y defensiva, favorece la implementación de la fuerza sin que previamente exista un ataque armado o inminente: basta la sospecha de una amenaza incierta, inminente e incluso futura para proceder. Vemos así, que la lógica unilateralista neoconservadora no puede estar supeditada a una autorización previa -para actuar- del Consejo de Seguridad (CSNU) o a cualquier otra organización como la OTAN, en tanto la decisión no puede depender de terceros. Bastará con la legalidad constitucional de los Estados Unidos, como único requisito jurídico y político, para poder accionar. En este mismo sentido parecería alinearse la nueva administración. No es casual que el mismo Trump, a poco de arribar al Salón Oval, se haya referido a la OTAN como una organización "obsoleta" ${ }^{48}$, mientras que, respecto de la ONU, había minimizado su relevancia -ya siendo presidente electo- al reducirla a "Un club de gente para reunirse, hablar y pasárselo bien". ${ }^{49}$

Más aún, los principios de no injerencia en los asuntos internos y el de probibición del uso de la fuerza fueron soslayados en la primera decisión significativa, en materia de política exterior, de la Era Trump: la embestida a la base aérea siria en Homs, el 7 de abril, como respuesta al (aún incierto) ataque con armas químicas dispuesto por el presidente sirio, Bashar al-Assad, el pasado 4 de abril, que dejó como resultado 83 víctimas fatales en Jan Sheijun. Sorteando por completo la instancia del CSNU, único habilitado -a tenor del Derecho Internacional- para disponer el uso de la fuerza armada ${ }^{50}$, ignorando al Congreso americano e incluso sin certezas respecto de que el impulsor de la acción fue al-Assad, Trump dispuso sin más la detonación de 59 misiles Tomahawk bajo el pretexto de salvaguardar a la población civil siria de futuros ataques químicos.

Aquí creo prudente hacer una aclaración. Es que tomando de base ciertas frases de Trump como "No child of god should ever suffer such horror", abogados internacionalistas como David Tafuri, sostienen la legalidad del uso de la fuerza y de la injerencia en la soberanía de la República Árabe

47. Cooper, D., Neconservatism and American Foreign Policy. A critical analysis (Nueva York: Routledge, 2011),142-143; Iglesias Cavicchioli, M., "La Doctrina Neoconservadora y el Excepcionalísimo americano...”, 18. Según entiende este autor, la idea surge finalizada la Guerra Fría, como un medio de acción necesario para consolidar la hegemonía americana. Ello, surge en la primera versión de la Defense Policy Guidance de 1992 elaborada por Paul Wolfowitz y Richard Cheney.

48 "Para Donald Trump, "la OTAN está obsoleta", La Nación, disponible en: http://www.lanacion.com.ar/1976208-paradonaldtrump-la-otan-esta-obsoleta

49 "Trump critica ahora a la ONU", El Mundo, disponible en: http://www.elmundo.es/internacional/2016/12/27/58620e7c468aeb49158b45c0.html

50 Carta de Naciones Unidas, Art. 42. 
Siria en el precitado concepto de R2P, entendiendo que éste era, por un lado, el único remedio pasible de ser utilizado ante la violación masiva de derechos humanos por parte de un Estado contra su propia población civil y, por otro, que se justificó la decisión ante la parálisis que sufre el Consejo de Seguridad por los reiterados vetos de Rusia y China. Si bien a la luz de ciertos enfoques estos argumentos podrían ser atendibles ${ }^{51}$, lo cierto es que Tafuri respalda la viabilidad de este recurso tanto en la costumbre internacional, como en la única ocasión en que se implementó la intervención militar bajo la noción de R2P, donde se autorizó a la OTAN a intervenir en Libia, en marzo de $2011 .^{52}$

Entiendo que ni uno ni otro argumento son aceptables. Respecto de que el R2P es parte de la costumbre internacional, autores de trascendencia en la materia, como Michael P. Scharf, quien incluso respalda la "creación acelerada del derecho internacional" a partir de esta fuente formal, considera que el R2P no puede, aún, ser considerada como parte integrante del derecho consuetudinario $^{53}$. Por otro lado, la situación actual de Libia es paupérrima, prácticamente es un Estado Fallido controlado por un poder central atomizado y resistido por diversos grupos armados e incluso, cuenta con presencia de células del Estado Islámico en su territorio ${ }^{54}$; todo ello impide aseverar, como lo hace Tafuri, que la intervención de la OTAN "was a success in saving lives and is still appreciated by nearly all Libyan citizens as a crucial decision". ${ }^{5}$

Dejando de lado esta cuestión, en otro orden, la corriente neoconservadora ha redefinido la concepción del Derecho Internacional Humanitario o ius in bello al abordar desde otra perspectiva las disposiciones del Estatuto del Prisionero de Guerra (POW Status en inglés), previstas en el III Convenio de Ginebra del 12 de agosto de 1949. Es que, al menos en el escenario de la Guerra contra el Terror, estas normas resultan improcedentes en tanto y en cuanto "protegen" a los terroristas en lugar de a sus víctimas.

En rigor, esta postura ha sido asumida en el contexto post 11-S y de la USA PATRIOT Act por la Administración Bush, el mencionado neoconservador John Yoo. Aquel consideraba que, tanto los miembros de Al-Qeada como los Talibanes capturados durante la Guerra de Afganistán (2001-2015), no tenían derecho a acogerse al POW Status toda vez que, al atacar a población civil indefensa y al haber violado normas fundamentales del Derecho Internacional, se veían privados de los derechos y la protección de las Convenciones de Ginebra. Así, concluía

51 Arredondo, R., Intervención Humanitaria y Responsabilidad de Proteger ¿̇hacia un nuevo paradigma de protección de los derechos humanos? (Buenos Aires: ISEN, 2012), 54-55.

52 Resolución S/Res/1973/2011 -Inc. 4º - del Consejo de Seguridad de las Naciones Unidas, 17 de marzo de 2011.

53 Scharf, M. P., "Accelerated Formation of Customary International Law", Scholarly Commons, School of Law (Cleveland, Case Western Reserve University, 2014), 337.

54 "The current situation in Libya", United States Institute of Peace, disponible en: https://www.usip.org/publications/2016/05/currentsituation-libya

55 "Why Trump's attack on Syria is legal?", David Tafuri, disponible en: http://www.politico.com/magazine/story/2017/04/donaldtrump-syria-attack-legal-215022

Número de página no utilizable para citar 
Yoo: "To ignore these fundamental distinctions poses a threat to US national security and undermines the very purpose and function of international humanitarian law". 56

De este modo, los prisioneros de guerra han sido considerados "combatientes ilegales" (unlawful combatants), una "nueva noción, inexistente en el Derecho Internacional Humanitario que ha situado a las personas afectadas en una especie de limbo jurídico" ${ }^{57}$, y que ha permitido, entre otras cosas, que permanezcan recluidos, sin cargos formales en muchos casos, en prisiones como Guantánamo a la espera de ser juzgados por tribunales militares especiales. De hecho, esto también ha favorecido la comisión de actos de tortura como el de la cárcel iraquí en Abu Ghraib o los vuelos secretos de la CIA y los interrogatorios "duros" en centros clandestinos de detención.

En tal sentido y a juzgar por las primeras declaraciones de Trump, no parecería que esta postura fuese a variar con la nueva administración. Sin ir muy lejos, al ser preguntado sobre la "tortura" como un medio para "quebrar" a los acusados de terrorismo, el propio Trump indicó que consultó a los oficiales de inteligencia si dichas técnicas traen buenos resultados y la respuesta fue afirmativa. A ello, Trump agregó que quiere hacer "todo dentro de los límites de lo que se le permite hacer legalmente" 58 sin perjuicio de no referirse a que, figuras como la de "combatientes ilegales", en tanto deformación de un concepto acordado y pasado en derecho consuetudinario, escapa a todo resquicio de legalidad.

Entonces bien, hasta aquí he intentado reflejar algunas de las posiciones más representativas tomadas por los excepcionalistas neoconservadores respecto del Derecho Internacional mientras que he pretendido enlazar ello con la administración del flamante presidente Donald J. Trump. Desde ya, una inevitable restricción de espacio me impide profundizar el análisis. No obstante, a modo de disparador y para fomentar la curiosidad, debo decir que he tenido que hacer a un lado la postura americana neoconservadora respecto del Crimen de Agresión y las invasiones a Afganistán e Irak o en relación con las sentencias de la Corte Internacional de Justicia; que obvié ahondar en tópicos sensibles como la Convención de los Derechos del Niño y Estados Unidos como único país del planeta que hoy día no la ha ratificado o en su postura respecto de la descolonización y el derecho de la libre determinación de los pueblos.

56 Yoo, J., "The Status of Soldiers and Terrorist under the Geneva Conventions", Chinese J. Int' L. vol. 3 (California, 2004), 150.

57 García Segura, C. y Rodrigo, Á., Los límites del proyecto imperial. Estados Unidos y el orden internacional en el Siglo XXI (Madrid: La Catarata, 2008), 129.

58 "Trump says torture works, US will review policies in War on Terror", Fox News, disponible en: http://www.foxnews.com/politics/2017/01/26/trump-says-torture-works-us-will-review-policies-in-war-on-terror.html 


\section{Reflexiones finales}

Acierta Samuel Huntington al señalar que Estados Unidos es el único país con preeminencia en todo dominio de poder -económico, militar, diplomático, ideológico, tecnológico y cultural- con la capacidad de promover sus intereses virtualmente en todas las partes del mundo. No caben dudas de su excepcionalidad en este mundo uni-multipolar. Sin embargo, desde el enfoque ensayado, lo cierto es que esa posición diferencial perturba, excede, altera y confunde el sistema jurídico internacional. En definitiva, desordena una estructura normativa que, carente de law enforcement y basada en la coordinación inter pares, requiere del respeto y la conciencia de sus actores.

En vista a los primeros pasos de Trump en la Casa Blanca, y a la luz de los postulados abordados en materia de Derecho Internacional, no consideraría que nos enfrentemos al fin del excepcionalismo americano. Quienes auguraban el final de esta doctrina, entiendo que - razonablemente- lo han hecho respaldados en algunas de las tantas frases de un presidente verborrágico y en la representación de Trump como un outsider en la política estadounidense. No obstante, a poco de atravesar su oscilante discurso, que parecería atentar contra todos los presupuestos de la excepcionalidad, se advierte -al menos en materia de Derecho Internacional- una posición alineada con la escuela neoconservadora.

Aun así, no podría decir que Trump y, en definitiva EEUU, “niega” el Derecho Internacional. En rigor, hemos visto que la corriente neoconservadora no le da la espalda a esta disciplina sino que se encarga, cuanto menos, de legitimar sus acciones reinterpretando los postulados de la materia. Dicho de otro modo, sin salirse del sistema Estados Unidos ensancha, estira o flexibiliza los principios rectores para permanecer dentro de él.

No obstante, creo firmemente en la preponderancia del Derecho Internacional y por tanto, considero que no son sanas para su desarrollo las excepciones a la regla. Su delicado sistema, ausente de coerción, al verse trasgredido sólo favorece más transgresiones.

A modo de conclusión, estimo que el reencause americano en el Derecho Internacional podría lograrse desafiando la postura excepcionalista. Esta puesta en crisis, sólo tendrá éxito si los Estados occidentales -principalmente los europeos, en gran parte responsables de la situación de excepcionalidad- se comprometen a alejarse de la cosmovisión subyacente que plantea la civilización occidental como la etapa más alta de un proceso de desarrollo humano unilineal e inevitable, y al Estado americano como su exponente más avanzado.

No será fácil, claro está, pero sólo así Estados Unidos dejará de confiar únicamente en Dios y, tal vez, logre hacerlo en el Derecho Internacional. 